OPEN ACCESS

Edited by:

Emmanuel Pinteaux,

The University of Manchester,

United Kingdom

Reviewed by:

Chun-sheng Yang,

Tianjin Medical University

General Hospital, China Rishein Gupta,

University of Texas at San Antonio,

United States

${ }^{*}$ Correspondence: Xiaofeng Yang

zjcswk@zju.edu.cn

Zuobing Chen

czb1971@zju.edu.cn

${ }^{t}$ These authors have contributed equally to this work and

share first authorship

Specialty section:

This article was submitted to

Multiple Sclerosis and

Neuroimmunology,

a section of the journal

Frontiers in Immunology

Received: 16 January 2021 Accepted: 04 May 2021

Published: 17 May 2021

Citation:

Sun $Y$, Wen $Y$, Wang $L$, Wen $L$, You W, Wei $S$, Mao L, Wang $H$,

Chen $Z$ and Yang $X$ (2021)

Therapeutic Opportunities of Interleukin-33 in the

Central Nervous System.

Front. Immunol. 12:654626. doi: 10.3389/fimmu.2021.654626

\section{Therapeutic Opportunities of Interleukin-33 in the Central Nervous System}

\author{
Yun Sun ${ }^{1 \dagger}$, Yankai Wen ${ }^{2 \dagger}$, Luxi Wang ${ }^{3 \dagger}$, Liang Wen ${ }^{4}$, Wendong You ${ }^{4}$, Shuang Wei ${ }^{1}$, \\ Lin Mao ${ }^{1}$, Hao Wang ${ }^{4}$, Zuobing Chen ${ }^{1 *}$ and Xiaofeng Yang ${ }^{4 *}$ \\ ${ }^{1}$ Department of Rehabilitation Medicine, The First Affiliated Hospital, Zhejiang University, Hangzhou, China, ${ }^{2}$ Department of \\ Anesthesiology, McGovern Medical School, University of Texas Health Science Center at Houston, Houston, TX, \\ United States, ${ }^{3}$ Department of Neurology, The First Affiliated Hospital of Wenzhou Medical University, Wenzhou, China, \\ ${ }^{4}$ Department of Neurosurgery, The First Affiliated Hospital, Zhejiang University, Hangzhou, China
}

Interleukin-33 (IL-33), a member of the IL-1 cytokine family, is involved in various diseases. IL-33 exerts its effects via its heterodimeric receptor complex, which comprises suppression of tumorigenicity 2 (ST2) and the $\mathrm{IL}-1$ receptor accessory protein (IL-1RAP). Increasing evidence has demonstrated that IL-33/ST2 signaling plays diverse but crucial roles in the homeostasis of the central nervous system (CNS) and the pathogenesis of CNS diseases, including neurodegenerative diseases, cerebrovascular diseases, infection, trauma, and ischemic stroke. In the current review, we focus on the functional roles and cellular signaling mechanisms of IL-33 in the CNS and evaluate the potential for diagnostic and therapeutic applications.

Keywords: interleukin-33, ST2, multiple sclerosis, ischemic stroke, trauma, hemorrhage, Alzheimer's disease, anti-inflammatory macrophages

\section{INTRODUCTION}

Interleukin-33 (IL-33) was originally discovered in 1999 as clone DVS27 in vasospastic cerebral arteries in a canine model of subarachnoid hemorrhage (SAH) (1) (Figure 1). Then, in 2003, IL-33 was identified as nuclear factor from high endothelial venules (NF-HEV), a nuclear factor preferentially expressed in human high endothelial venules (2). In 2005, IL-33 was classified as a member of the IL-1 cytokine family and named IL-1F11 (3). Remarkably, IL-33 is continuously expressed in healthy brains and spinal cords (4), which have higher IL-33 mRNA expression than any other tissue tested (3). In recent years, IL-33 has been found to be involved in various disorders of the central nervous system (CNS), including multiple sclerosis (MS) $(5,6)$, infection $(7,8)$, ischemic stroke $(9,10)$, traumatic brain injury (TBI) $(11,12)$, spinal cord injury $(\mathrm{SCI})(4,13)$, brain tumorigenesis $(14,15)$, and mental disorders (16) (Figure 2). In the current review, we will focus on the functional roles and cellular signaling mechanisms of IL-33 in the CNS and evaluate the potential for diagnostic and therapeutic applications. 


\section{IL-33 AND ITS RECEPTOR}

Human IL-33 is located on chromosome 9p24.1 and encodes 270 amino acids, while its mouse counterpart is located on the syntenic chromosome 19qC1 region and encodes 266 amino acids.
At the amino acid level, human and mouse IL-33 are 55\% identical (3). IL-33 can be confined in the nucleus as a result of binding heterochromatin with an evolutionarily conserved homeodomain-like helix-turn-helix motif within its N-terminal region (17). However, under pathological conditions, IL-33 is

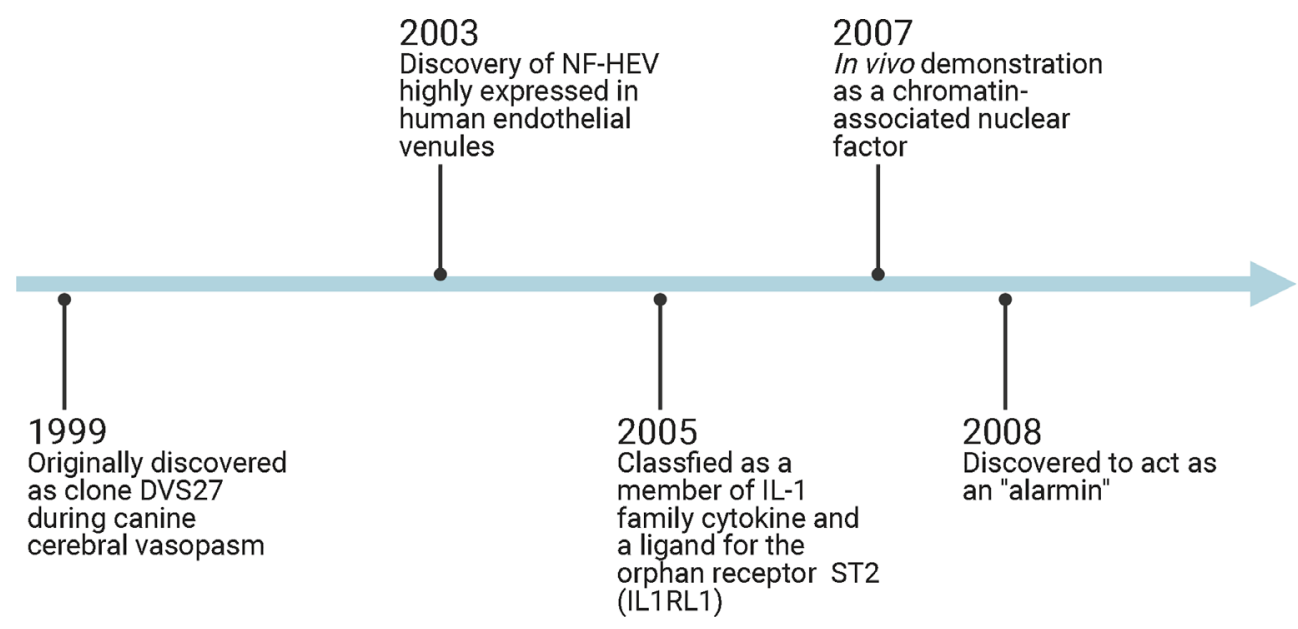

FIGURE 1 | Timeline diagram demonstrates IL-33-related discoveries. HF-HEV: nuclear factor from high endothelial venules; IL1RL1: interleukin 1 receptor-like 1; ST2: suppression of tumorigenicity 2.

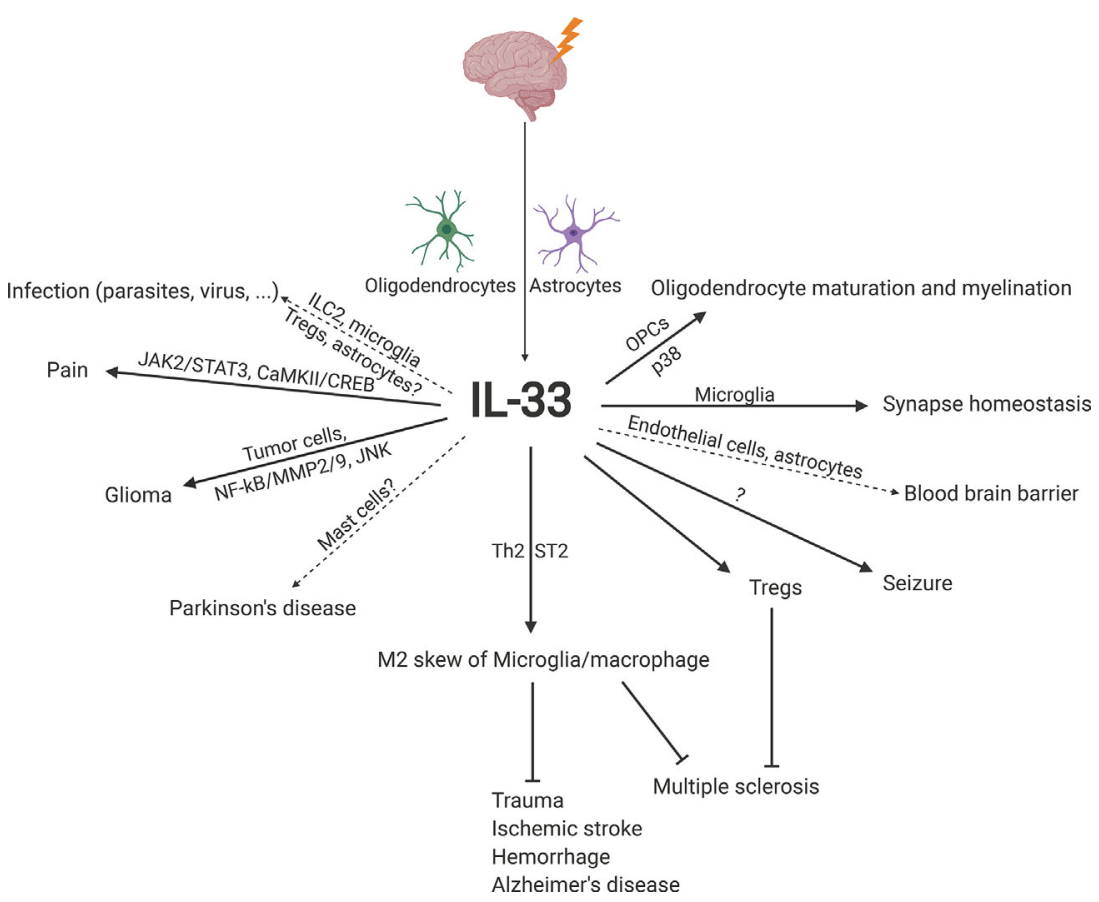

FIGURE 2 | Schematic overview of the roles and underlying signaling mechanisms of IL-33 in CNS homeostasis and disease. CaMKII, calcium-calmodulindependent kinase II; CREB, cyclic adenosine monophosphate response element-binding protein; IL-33, interleukin-33; ILC2, group 2 innate lymphoid cell; JAK2,

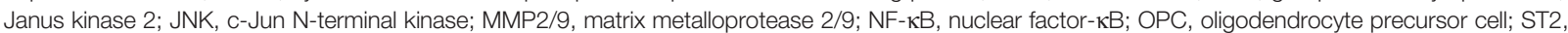
suppression of tumorigenicity 2; STAT3, signal transducer and activator of transcription 3; Th2, T helper type 2; Treg, regulatory T cell. 
released by stressed or damaged cells as an alarmin (18-20). IL-33 is released in either a full-length or cleaved form. Unlike IL-1 $\beta$, IL-33 is not cleaved by caspase-1 (21). Instead, processing by caspase-1, caspase-3, and caspase-7 actually leads to IL-33 inactivation $(22,23)$. Other proteins, such as neutrophil elastase, cathepsin G (24), chymase and tryptase $(25,26)$, cleave IL-33, and the resulting cleaved IL-33 has much higher biological activity than full-length IL-33.

Extracellular IL-33 exerts its effects by binding to the orphan receptor suppression of tumorigenicity 2 (ST2, also known as IL1RL1, DER4, T1 and FIT-1) (3). Upon binding IL-33, ST2 on the cell membranes forms a heterodimer with IL-1 receptor accessory protein (IL-1RAP) $(27,28)$, which leads to the dimerization of the Toll/interleukin-1 receptor (TIR), the subsequent recruitment of myeloid differentiation primary response protein $88(\mathrm{MyD} 88)$ and the activation of IL-1Rassociated kinase, and ultimately activate the mitogen-activated protein kinase (MAPK) and nuclear factor- $\kappa \mathrm{B}(\mathrm{NF}-\kappa \mathrm{B})$ signaling pathways $(3,29)$.

Notably, four isoforms of ST2 exist: transmembrane ST2L, soluble ST2 (sST2), ST2V and ST2LV. ST2L and sST2 come from a dual promoter system to drive differential mRNA expression (30). Transmembrane ST2L contains transmembrane and cytoplasmic domains that are absent in sST2 (31). sST2 has been reported to be a decoy receptor that competes with ST2L for IL-33 binding, thus inhibiting the IL-33 signaling pathway (32, 33). ST2V and ST2LV are two splice variants of ST2. ST2V gains a hydrophobic tail instead of losing the third immunoglobulinlike domain in the C-terminal portion of ST2L (34), while ST2LV is produced from deletion of the transmembrane domain of ST2L (35). To date, there have been no reports in the literature of the interaction of IL-33 with ST2V or ST2LV.

In addition to sST2, other factors have been reported to inhibit IL-33/ST2 signaling by regulating ST2. For example, single immunoglobulin domain IL-1R-related molecule (SIGIRR, also known as TIR8) forms a complex with ST2 upon IL-33 stimulation and subsequently inhibits IL-33mediated signaling $(36,37)$. Another negative regulator is Fbox and leucine-rich repeat protein 19 (FBXL19), which mediates the ubiquitination and degradation of ST2 (38).

\section{IL-33 IN CNS DEVELOPMENT AND HOMEOSTASIS}

IL-33 expression was first detected in the mouse CNS during late embryogenesis, and its expression increased from postnatal day 2 (P2) to P9 then declined and became absent after P23. During this period, astrocytes and oligodendrocyte precursor cells (OPCs) rather than neurons are responsible for IL-33 expression $(39,40)$. IL-33 induces the expression of myelin basic protein and the transcription of myelin genes via p38 MAPK activation in OPCs in vitro (41). Conversely, IL-33 deficiency disrupts OPC differentiation into oligodendrocytes and interferes with myelin compaction in vitro and in vivo (42), indicating a potential role of IL-33 in oligodendrocyte maturation and myelination during CNS development. During the early period of postnatal synapse maturation, IL-33 expression increases in astrocytes but only in a subpopulation of spinal cord and thalamic astrocytes in gray matter, where most synapses are located. This IL-33 induction is developmentally crucial for neural circuit function and ST2-expressing microglial synapse engulfment in the spinal cord and thalamus. IL-33deficient mice have deficits in the acoustic startle response, which is a sensorimotor reflex mediated by motor neurons in the brainstem and spinal cord. Furthermore, in IL-33-deficient mice, spontaneous and evoked oscillatory activity increases in an intrathalamic circuit between the ventrobasal nucleus and the reticular nucleus of the thalamus (40), which implies that IL-33 is required to maintain synapse homeostasis during CNS development.

IL-33 is constitutively expressed in the corpus callosum, hippocampus, thalamus, and cerebellum (granular layer and white matter) in adulthood, which was discovered using IL-33LacZ gene trap reporter adult mice (43). It is predominantly expressed in astrocytes in both the brain and spinal cord in mice. IL-33 is also expressed in oligodendrocytes, microglia, and neurons, but at a lower level (16). ST2 expression is found in neurons and glial cells in the brain and spinal cord in rodents. Notably, the expression of ST2 on cerebral endothelial cells and astrocytes close to the endothelial layer of the cortex implies a role of IL-33/ST2 signaling in maintaining the function of the blood brain barrier (BBB) $(16,44)$. Despite the fact that IL-33 protein is always localized in the nucleus of cells as an alarmin (43), whether the nuclear IL-33 impacts CNS homeostasis is unclear.

\section{IL-33 IN MULTIPLE SCLEROSIS}

Multiple sclerosis (MS) is an autoimmune disease characterized by demyelination and neurodegeneration in the CNS. IL-33 is elevated in plasma, normal-appearing white matter, and lesions in MS patients compared to normal controls $(5,45)$. In experimental autoimmune encephalomyelitis (EAE) mice, a widely used mouse model of MS, the expression levels of IL-33 and ST2 in the spinal cord are elevated compared to those in naïve mice $(46,47)$.

The role of IL-33/ST2 signaling in MS has been intensively investigated in mice. Although one group demonstrated that blockade of IL-33 protected mice against EAE (46), most literature suggests that IL-33 is a protective factor. Exogenous IL-33 can significantly suppress EAE in mice (48-50). Conversely, either IL-33 antibody or genetic ablation exacerbates EAE development in mice $(47,51)$. In addition, ST2-deficient mice develop aggravated EAE that cannot be restored by exogenous IL-33 injection (48, 52). Several mechanisms are involved in IL-33-attenuated EAE. First, IL-33 reduces the frequency of $\mathrm{IL}_{-17 \mathrm{~A}^{+}}$and interferon gamma ${ }^{+}$ $\left(\mathrm{IFN} \gamma^{+}\right.$) cells in both draining lymph nodes (DLNs) and spleens $(48,51,52)$. This is probably due to the attenuated inflammatory phenotype of antigen-presenting cells (APCs) 
upon IL-33/ST2 activation. Transplantation of dendritic cells (DCs) from DLNs and spleens of ST2-deficient $\mathrm{MOG}_{35-55^{-}}$ immunized EAE mice to wild-type counterparts exacerbates EAE development (52). Second, IL-33 protects EAE mice via regulatory $\mathrm{T}$ cells (Tregs), which are ST2 positive (53). IL-33 significantly increases the frequency of Tregs in the spinal cords of EAE mice (48). Consistent with these results, Tregs are enriched within MS lesions but not in remyelinating lesions in patients and produce IL-10, which facilitates the resolution of MS (54). Third, IL-33 polarizes macrophages in DLNs and spleens toward the anti-inflammatory M2 phenotype. Transplantation of macrophages from lymph nodes (LNs) and spleens of IL-33-treated mice to immunized mice attenuates EAE development (48). Last, other cell types educated by IL-33 exert protective roles. For example, IL-33treated eosinophil transplantation confers protection against EAE in mice (50). ST2-expressing mast cells, group 2 innate lymphoid cells (ILC2s) and basophils are also implied to produce anti-inflammatory IL-4 and/or IL-13 to protect against EAE in mice (49).

Furthermore, experiments using rat in vitro myelinating coculture have suggested that IL-33 inhibits axon myelination during MS pathogenesis (45). However, IL-33 has also been reported by another group to promote myelin repair (41). Therefore, the direct effect of IL-33 on myelination and the underlying mechanisms need to be further investigated. Taken together, these studies show that IL-33 has a protective effect in a mouse model of EAE and might be a promising therapeutic target for MS patients.

\section{IL-33 IN TRAUMA}

IL-33 has been reported to be increased in microdialysate samples of patients with TBI (11). Serum sST2 levels are also elevated in TBI patients, and the increased concentrations are positively related to inflammation, severity and prognosis (55), which indicates that $\mathrm{SST} 2$ is a potential prognostic biomarker for TBI. In mice, IL-33 is released immediately from damaged oligodendrocytes and astrocytes in injured CNS tissue during TBI induced by controlled cortical impact (CCI) and experimental SCI $(4,11,13,56)$.

After CCI or SCI, ST2- or IL-33-deficient mice exhibit attenuated induction of chemokines in local astrocytes, such as C-C motif chemokine ligand 2 (CCL2), which subsequently impairs inflammatory monocyte infiltration $(4,11)$. Consistent with these results, treatment with recombinant IL-33 alleviates secondary damage by significantly decreasing tissue loss, demyelination and astrogliosis in the contused mouse spinal cord, which contributes to improved functional recovery (13). IL-33 prevents TBI-induced inflammation and apoptosis in mice (56). In addition, IL-33 augments the skew of macrophages toward the M2 phenotype $(4,13)$, which is beneficial after CNS injury. However, the underlying mechanism by which IL33/ST2 signaling drives the anti-inflammatory response in CNS trauma needs to be further investigated.

\section{IL-33 IN ISCHEMIC STROKE}

The concentrations of both IL-33 and sST2 increase in circulating blood in patients with ischemic stroke $(9,10,57$, 58 ), and both are negatively correlated with patient outcome and can serve as independent diagnostic and predictive prognostic markers in ischemic stroke patients $(10,58,59)$. Besides, two ongoing clinical trials in United States (NCT03297827) and Poland (NCT03948802) are evaluating the utility of IL-33 as a biomarker of acute stroke. And another active clinical trial in Croatia (NCT04607031) is determining the prognostic accuracy of sST2 dynamics in ischemia stroke outcomes. The results from these clinical trials will provide further evidence to determine whether IL-33 and sST2 are the reliable biomarkers for stroke patients.

In the mouse model of ischemic stroke induced by middle cerebral artery occlusion (MCAO), IL-33 mRNA and protein expression are obviously upregulated in lesions, and mature oligodendrocytes and astrocytes are responsible for this upregulation $(9,60-62)$.

ST2 or IL-33 deficiency exacerbates ischemic brain injury after MCAO in mice $(60,61)$. Conversely, exogenous IL-33 treatment protects mice against experimental ischemic stroke (9, 63-65) and neonatal hypoxic ischemic brain injury (62). Mechanistically, IL-33 does not directly act on neurons. Instead, similar to trauma, IL-33 reduces astrocyte activation and drives the type 2 response (9). Two pathways might be involved in the IL-33-driven skew of microglia/macrophages toward the M2 phenotype after MCAO. First, it has been reported that IL-33 increases peri-ischemic IL-4 secretion from T cells in the brain, contributing to the skew toward M2 macrophages. Moreover, the IL-4 antibody treatment abrogates IL-33-mediated protection in mice after MCAO (9). Second, IL-33 directly potentiates M2 polarization of microglia/macrophages via an unknown signaling pathway after MCAO $(57,60)$. Another mechanism involved in IL-33-mediated protection in ischemic stroke is promotion of the T helper type 2 (Th2) response and suppression of Th1 and Th17 responses $(63,65)$.

Surprisingly, blockade of CD25 on Tregs fails to abrogate IL33-mediated protection in mice after MCAO (9), even though $\mathrm{ST}^{+}$Tregs are observed to increase in ischemic brain and spleen in MCAO mice upon IL-33 treatment (64-67) and IL-33/ST2 signaling has been suggested to play an important role in the expansion and function of brain Tregs (68); this result indicates that the expanded Tregs in MCAO mice are only bystanders. In summary, IL-33 treatment might be a promising therapeutic method for ischemic stroke patients.

\section{IL-33 IN HEMORRHAGE}

As previously described, IL-33 was initially identified as one of the differentially expressed genes in vasospastic cerebral arteries after SAH in dogs (1). It was then reported that IL-33 protein and mRNA levels increase in the brain cortex in a rat model of SAH, and IL-33 is mainly localized in neurons (69). However, in the 
rodent model of intracerebral hemorrhage (ICH), IL-33 mainly localizes in astrocytes and microglia rather than in neurons in the brain around the hematoma of the ipsilateral hemisphere. Furthermore, exogenous IL-33 exerts a neuroprotective effect against $\mathrm{ICH}$ via selective microglial M2 polarization and subsequent inflammatory suppression $(70,71)$.

\section{IL-33 IN INFECTION}

The cerebral complications of malaria, which is caused by Plasmodium falciparum infection, are associated with longterm neurological sequelae in survivors. IL-33 expression in oligodendrocytes and astrocytes is increased in the mouse brain during Plasmodium berghei ANKA (PbA) infectioninduced experimental cerebral malaria (ECM) as well as during other parasitic infections, including Toxoplasma gondii and Angiostrongylus cantonensis (8, 72-75). ST2 deficiency disrupts ECM infection, prevents recognition impairment and improves survival in mice with $\mathrm{PbA}$ infection, and these effects might be attributed to the suppression of IL-1 $\beta$ production by ST2deficient microglia and the impaired sequestration and activation of pathogenic $\mathrm{T}$ cells $(8,72)$. Interestingly, two other groups reported other scenarios. One group used IL-33-deficient mice to demonstrate that IL-33 was not critical for ECM development (76). The other group elucidated that exogenous IL-33 protected mice from $\mathrm{PbA}$ infection-induced $\mathrm{ECM}$ by orchestrating a protective immune response via ILC2s, M2 macrophages and Tregs (77). These results are supported in Toxoplasma gondii-infected mice. Deletion of ST2 increases susceptibility to Toxoplasma gondii infection in mice due to the increased parasite burden in the brain $(74,75)$. Moreover, astrocytes without ST2 fail to recruit and/or maintain adequate antiparasitic IFN $\gamma$-expressing $\mathrm{T}$ cells and inducible nitric oxide synthase (iNOS)-expressing monocytes/macrophages in the CNS to control parasites (75).

Bacterial infection may induce endotoxemia, leading to neuroinflammation. Intracerebroventricular endotoxin (also known as lipopolysaccharide, LPS) induces IL-33 production by glia in the brain $(20,44)$. IL-33-deficient mice exhibit attenuated neuroinflammation upon LPS challenge. Microglia are the target cells that are stimulated by IL-33 to produce proinflammatory cytokines during LPS stimulation (44).

Furthermore, IL-33/ST2 signaling plays a role in virusinduced CNS diseases. In the newborn brain with Zika virusinduced microcephaly, IL-33 is significantly upregulated compared to that in newborn brains with microcephaly without virus infection $(78,79)$. IL-33 has been found to positively correlate with IL-1 $\beta$ expression $(79,80)$, implying that IL-33 might play a role in the proinflammatory response in virus infection. In addition, an in vitro study demonstrated that HIV infection induces IL-33 release from neurons and ST2 upregulation in astrocytes. A higher IL-33 concentration is associated with decreased synaptic plasticity due to enhanced neuroinflammation (81), indicating a deleterious role of IL-33 in neuropathogenesis in HIV infection. However, in an experimental mouse model of encephalitis induced by Rocio virus infection, ST2 knockout mice showed increased susceptibility to infection and an increased mortality rate, possibly attributable to increased iNOS production through local IFN $\gamma$ modulation (7). Taken together, these data suggest that more investigations are warranted to determine the role of IL-33/ST2 signaling in parasitic/viral infection.

\section{IL-33 IN TUMORS}

Glioma is the most frequent intracranial tumor in adult humans. It has been reported that IL-33 and ST2 expression in glioma tissues is higher than that in normal brain tissues, and their expression is positively correlated with glioma grade $(15,82)$. Moreover, higher IL-33 expression is associated with poor overall survival (OS) and recurrence-free survival (RFS) in patients with gliomas $(14,15,83)$, indicating that IL-33 might be an independent prognostic marker for glioma.

IL-33 is highly expressed in tumor cells during glioma development. It is believed that glioma cells are also ST2 positive. Knockdown of IL-33 or ST2 in glioma cell lines suppresses proliferation, migration and invasion in vitro and reduces tumor formation in vivo in both rodent models of intracerebral glioma cell implantation and subcutaneous xenograft (82-84). Mechanistically, IL-33/ST2 activates NF- $\kappa B$ signaling to induce matrix metalloprotease $2 / 9$ (MMP2/9) to enhance cell migration and invasion (82) and promotes c-Jun Nterminal kinase (JNK) signaling to induce the expression of key transcription factors that control the process of epithelial-tomesenchymal transition (EMT) and stemness (83). Notably, IL33 prevents temozolomide (TMZ)-induced brain tumor apoptosis, and blocking IL-33/ST2 signaling can increase the sensitivity of tumors to TMZ (83). On the other hand, a recent study demonstrated that glioma-derived IL-33 correlated with increased tumor-associated macrophages/microglia in human specimens and in mice with intracerebral xenografts. The group reported that ST2 expression was minimal on glioma cells and that nuclear IL-33 mediated the release of inflammatory cytokines from glioma cells and was required for the recruitment of M2 protumorigenic macrophages (85).

An anticancer role of ST2 has been proposed. ST2 binds to tumor cell apoptosis factor (TCApF), a peptide naturally expressed in the frontal lobe of the brain, to activate caspase-3-, caspase-8-, and caspase-9-mediated apoptosis (86). However, whether IL-33 competes with TCApF for ST2 binding in glioma is unclear. Nevertheless, IL-33 might be a promising therapeutic target for glioma.

\section{IL-33 IN ALZHEIMER'S DISEASE AND PARKINSON'S DISEASE}

Although IL-33-positive cells (astrocytes and microglia) are significantly increased in Alzheimer's disease (AD) brains compared to non-AD brains (87), IL-33 mRNA expression in the brain (88) and circulating IL-33 levels (89) are lower in AD patients 
than in healthy controls. The decreased circulating IL-33 levels in $\mathrm{AD}$ might be attributed to the increased decoy receptor SST2 in the blood of $\mathrm{AD}$ patients (89). Three single nucleotide polymorphisms (SNPs), rs1157505, rs11792633 and rs7044343, within IL-33 have been reported to be associated with $\mathrm{AD}$ risk in a large prospective study in a Caucasian population. These polymorphisms are associated with less cerebral amyloid angiopathy (CAA) in the brain (88), which correlates closely with AD pathology. These SNPs were further evaluated in two independent cohorts in the Han Chinese population. It was reported that the IL-33 rs11792633 polymorphism was significantly associated with a reduced risk of late onset $\mathrm{AD}(\mathrm{LOAD})$ in patients and that the $\mathrm{T}$ allele was a protective factor for $\operatorname{LOAD}(90,91)$.

IL-33 has been suggested to prevent $\mathrm{AD}$ development in in vitro and in vivo animal studies. IL-33 overexpression in in vitro cellular models induces a specific decrease in the secretion of amyloid $\beta_{40}$ $\left(\mathrm{A} \beta_{40}\right)$ peptides, which are the main component of CAA (88). In the APPswe, PSEN1dE9 (APP/PS1) double transgenic mouse, an AD mouse model, IL-33 administration reduces soluble $A \beta$ levels and amyloid plaque deposition by enhancing microglial recruitment, $\mathrm{A} \beta$ phagocytic activity and anti-inflammatory responses via ST2/ MAPK signaling, ultimately contributing to the amelioration of AD development (92). Strikingly, compared to their wild-type counterparts, IL-33-deficient aged mice (aged 65-80 weeks) develop significant abnormal tau accumulation, which is a biomarker for $\mathrm{AD}$ (93), and late-onset neurodegeneration in the cerebral cortex and hippocampus accompanied by impaired cognition/memory. IL-33 deficiency induces impaired repair of DNA double-strand breaks and defective autophagic clearance of cellular waste in neurons (94). IL-33 might also contribute to repressing aging-associated neuroinflammation and cognitive decline via ILC2s. The ILC2s are ST2 positive and functionally quiescent at homeostasis but can be activated by IL-33 to produce a vast range of type 2 cytokines to combat aging-associated neurodegenerative disorders (95).

Increased IL-33-expressing astrocytes are detected in the midbrain and striatum of Parkinson's disease (PD) brains compared with age- and sex-matched control brains (96). In vitro studies have shown that 1-methyl-4-phenylpyridinium $\left(\mathrm{MPP}^{+}\right)$, a metabolite of the parkinsonian neurotoxin 1-methyl4-phenyl-1,2,3,6-tetrahydropyridine (MPTP), induces IL-33 release from astrocytes (97). Mast cells, a population of IL-33targeting cells whose activation is detected in PD brains, might contribute to neuroinflammation during PD development (96, 97). Together, IL-33 administration could be a potential therapy for AD. However, the role of IL-33 in PD remains elusive.

\section{IL-33 IN PAIN}

The role of IL-33/ST2 signaling in the pain response has been well characterized in different animal models. In various rodent models, IL-33 expression is increased in neurons, oligodendrocytes and/or astrocytes in the spinal cord (98-101). Either blocking ST2 genetically, intrathecal administration of an ST2-neutralizing antibody or IL-33 knockdown attenuates model-induced mechanical hyperalgesia and heat/cold allodynia (98-102). In the spared nerve injury (SNI) neuropathic pain model, IL-33 activates the astroglial Janus kinase 2 (JAK2)/signal transducer and activator of transcription 3 (STAT3) cascade and the neuronal calciumcalmodulin-dependent kinase II (CaMKII)/cyclic adenosine monophosphate response element-binding protein (CREB) cascade to contribute to nociceptive behaviors (98). On the other hand, IL-33-induced hyperalgesia, which is initiated by SNI (99), bone cancer (100), non-compressive lumbar disk herniation (101), or complete Freund's adjuvant (102), is inflammation dependent, indicating the involvement of microglia.

\section{IL-33 IN SEIZURE}

In SAH patients, plasma sST2 levels are higher among patients with new or worsening epileptiform abnormalities than those of patients without (103), implying that IL-33, which can be decoyed by sST2, is associated with reduced odds of epileptiform abnormalities. In a rat model of recurrent neonatal seizure (RNS), IL-33 administration restores the reduced IL-33 in the cortex induced by RNS, improves RNSinduced behavioral deficits, promotes body weight gain, and ameliorates spatial learning and memory ability by impeding NF-אB-mediated neuroinflammation $(104,105)$.

\section{IL-33 IN MENTAL DISORDERS}

Even though both IL-33 and sST2 levels in chronic schizophrenia patient sera are comparable with those in their control counterparts, serum IL-33 is positively correlated with cognitive performance in patients with schizophrenia (106). Furthermore, the IL-33 gene polymorphism (rs11792633) is associated with the development of schizophrenia. The CT and TT variants of rs11792633 are related with significantly reduced risk of schizophrenia (107).

IL-33 has also been implicated in other kinds of mental disorders. In women with a history of recurrent major depressive disorder, circulating IL-33 is higher than that in healthy controls (108). Another study found that IL-33 concentrations were significantly associated with increased odds of perinatal major depressive episodes (109). However, IL-33 levels in blood in children with autism spectrum disorder do not differ from control counterparts $(110,111)$. In contrast, elevated IL-33 expression in the brain is observed in BTBR $T+t f / \mathrm{J}$ (BTBR) mice, which exhibit several symptoms of autism, including reduced social interactions, restricted repetitive behaviors and unusual vocalizations (112). Interestingly, IL-33deficient mice exhibit reduced anxiety-like behaviors and impaired social novelty recognition via unknown signaling (113).

\section{IL-33 IN AMYOTROPHIC LATERAL SCLEROSIS}

IL-33 levels in serum is lower in patients with amyotrophic lateral sclerosis (ALS) than those in healthy controls (114). In the 
transgenic mice of ALS expressing G93A-superoxide dismutase 1 (SOD1-G93A), long-term IL-33 administration delays disease onset in females but not males probably through peripheral Th2 response (115).

\section{IL-33 IN NEURO-BEHÇET'S DISEASE}

Neuro-Behçet's disease (NBD) causes CNS complications and is present in 5-30\% of patients with Behçet's disease (BD) (116). IL33 has been reported to be significantly higher in the cerebrospinal fluid of patients of NBD compared with those of patients with headache attributed to $\mathrm{BD}$ and patients with noninflammatory neurological diseases. And expression of IL-33 mRNA in cerebrospinal fluid cells from patients with NBD is positively correlated with CCL2 and C-X-C motif chemokine ligand 10 (CXCL10) expression (117). Though IL-33 is implied to play a role in CNS inflammation in NBD patients, future investigations are warranted to determine whether and how the IL-33 plays a beneficial or detrimental role in CNS of patients with NBD.

\section{CONCLUSION}

IL-33 is induced predominantly in oligodendrocytes and astrocytes in the CNS. In addition to promoting brain tumorigenesis, IL-33 promotes M2 macrophage skew and/or Treg expansion and activation to establish an anti-inflammatory

\section{REFERENCES}

1. Onda H, Kasuya H, Takakura K, Hori T, Imaizumi T, Takeuchi T, et al. Identification of Genes Differentially Expressed in Canine Vasospastic Cerebral Arteries After Subarachnoid Hemorrhage. J Cereb Blood Flow Metab (1999) 19(11):1279-88. doi: 10.1097/00004647-199911000-00013

2. Baekkevold ES, Roussigne M, Yamanaka T, Johansen FE, Jahnsen FL, Amalric F, et al. Molecular Characterization of NF-HEV, a Nuclear Factor Preferentially Expressed in Human High Endothelial Venules. Am J Pathol (2003) 163(1):69-79. doi: 10.1016/S0002-9440(10)63631-0

3. Schmitz J, Owyang A, Oldham E, Song Y, Murphy E, McClanahan TK, et al. IL-33, an interleukin-1-like Cytokine That Signals Via the IL-1 ReceptorRelated Protein ST2 and Induces T Helper Type 2-Associated Cytokines. Immunity (2005) 23(5):479-90. doi: 10.1016/j.immuni.2005.09.015

4. Gadani SP, Walsh JT, Smirnov I, Zheng J, Kipnis J. The Glia-Derived Alarmin IL-33 Orchestrates the Immune Response and Promotes Recovery Following CNS Injury. Neuron (2015) 85(4):703-9. doi: 10.1016/ j.neuron.2015.01.013

5. Christophi GP, Gruber RC, Panos M, Christophi RL, Jubelt B, Massa PT. Interleukin-33 Upregulation in Peripheral Leukocytes and CNS of Multiple Sclerosis Patients. Clin Immunol (2012) 142(3):308-19. doi: 10.1016/ j.clim.2011.11.007

6. Zhang F, Tossberg JT, Spurlock CF, Yao SY, Aune TM, Sriram S. Expression of IL-33 and Its Epigenetic Regulation in Multiple Sclerosis. Ann Clin Trans Neurol (2014) 1(5):307-18. doi: 10.1002/acn3.47

7. Franca RF, Costa RS, Silva JR, Peres RS, Mendonca LR, Colon DF, et al. IL33 Signaling is Essential to Attenuate Viral-Induced Encephalitis Development by Downregulating iNOS Expression in the Central Nervous System. J Neuroinflamm (2016) 13(1):159. doi: 10.1186/s12974016-0628-1 microenvironment against diseases, especially $\mathrm{MS}, \mathrm{AD}$, trauma, ischemic stroke, and hemorrhage (Figure 2), which suggests that IL-33 administration is an appropriate and desired therapeutic treatment against CNS diseases.

Currently, most studies are linking increased IL-33 induced in injured CNS to anti-inflammatory microenvironment in local lesions and/or lymphatic tissues (spleen and LNs). However, IL33 is expressed in various organs (such as gut, lung, skin...), and plays a critical role in tissue homeostasis, injury and inflammation (118) as well as controlling gut microbiota (119, 120). Since targeting microbiota-gut-brain axis becomes new therapeutic strategy for neurological diseases (121), in the future, studies on the role of IL-33 from gut in microbiota-gutbrain axis might be emerging. Secondly, given that IL-33 is a powerful cytokine in a variety of organs and disease, the best strategy to deliver IL-33 to suppress inflammation in CNS without inducing side effect in other organs needs to be further investigated. Thirdly, current clinical trials using IL-33/ ST2 signaling to treat CNS diseases are totally blank. There is still a long way to go from bench to bedside for IL-33/ST2 therapy in CNS diseases.

\section{AUTHOR CONTRIBUTIONS}

Literature review and manuscript writing: YS, YW, and LWa. Language editing: LWe, WY, SW, LM, and HW. Design of review outline: XY, ZC, and YS. All authors contributed to the article and approved the submitted version.

8. Reverchon F, Mortaud S, Sivoyon M, Maillet I, Laugeray A, Palomo J, et al IL-33 Receptor ST2 Regulates the Cognitive Impairments Associated With Experimental Cerebral Malaria. PloS Pathog (2017) 13(4):e1006322. doi: 10.1371/journal.ppat.1006322

9. Korhonen P, Kanninen KM, Lehtonen S, Lemarchant S, Puttonen KA, Oksanen M, et al. Immunomodulation by Interleukin-33 is Protective in Stroke Through Modulation of Inflammation. Brain Behav Immun (2015) 49:322-36. doi: 10.1016/j.bbi.2015.06.013

10. Qian L, Yuanshao L, Wensi H, Yulei Z, Xiaoli C, Brian W, et al. Serum IL-33 is a Novel Diagnostic and Prognostic Biomarker in Acute Ischemic Stroke. Aging Dis (2016) 7(5):614-22. doi: 10.14336/AD.2016.0207

11. Wicher G, Wallenquist U, Lei Y, Enoksson M, Li X, Fuchs B, et al Interleukin-33 Promotes Recruitment of Microglia/Macrophages in Response to Traumatic Brain Injury. J Neurotrauma (2017) 34(22):317382. doi: $10.1089 /$ neu. 2016.4900

12. Erenler AK, Baydin A. Interleukin-33 (IL-33) as a Diagnostic and Prognostic Factor in Traumatic Brain Injury. Emergency Med Int (2020) 2020:1832345. doi: $10.1155 / 2020 / 1832345$

13. Pomeshchik Y, Kidin I, Korhonen P, Savchenko E, Jaronen M, Lehtonen S et al. Interleukin-33 Treatment Reduces Secondary Injury and Improves Functional Recovery After Contusion Spinal Cord Injury. Brain Behav Immun (2015) 44:68-81. doi: 10.1016/j.bbi.2014.08.002

14. Gramatzki D, Frei K, Cathomas G, Moch H, Weller M, Mertz KD Interleukin-33 in Human Gliomas: Expression and Prognostic Significance. Oncol Lett (2016) 12(1):445-52. doi: 10.3892/ol.2016.4626

15. Zhang J, Wang P, Ji W, Ding Y, Lu X. Overexpression of Interleukin-33 is Associated With Poor Prognosis of Patients With Glioma. Int J Neurosci (2017) 127(3):210-7. doi: 10.1080/00207454.2016.1175441

16. Fairlie-Clarke K, Barbour M, Wilson C, Hridi SU, Allan D, Jiang HR. Expression and Function of IL-33/ST2 Axis in the Central Nervous System 
Under Normal and Diseased Conditions. Front Immunol (2018) 9:2596. doi: 10.3389/fimmu.2018.02596

17. Carriere V, Roussel L, Ortega N, Lacorre DA, Americh L, Aguilar L, et al. IL33, the IL-1-like Cytokine Ligand for ST2 Receptor, is a ChromatinAssociated Nuclear Factor In Vivo. Proc Natl Acad Sci USA (2007) 104 (1):282-7. doi: 10.1073/pnas.0606854104

18. Moussion C, Ortega N, Girard JP. The IL-1-like Cytokine IL-33 is Constitutively Expressed in the Nucleus of Endothelial Cells and Epithelial Cells In Vivo: A Novel 'Alarmin'? PloS One (2008) 3(10):e3331. doi: 10.1371/journal.pone.0003331

19. Yasuoka S, Kawanokuchi J, Parajuli B, Jin S, Doi Y, Noda M, et al. Production and Functions of IL-33 in the Central Nervous System. Brain Res (2011) 1385:8-17. doi: 10.1016/j.brainres.2011.02.045

20. Hudson CA, Christophi GP, Gruber RC, Wilmore JR, Lawrence DA, Massa PT. Induction of IL-33 Expression and Activity in Central Nervous System Glia. J Leukoc Biol (2008) 84(3):631-43. doi: 10.1189/jlb.1207830

21. Talabot-Ayer D, Lamacchia C, Gabay C, Palmer G. Interleukin-33 is Biologically Active Independently of Caspase-1 Cleavage. I Biol Chem (2009) 284(29):19420-6. doi: 10.1074/jbc.M901744200

22. Cayrol C, Girard JP. The IL-1-like Cytokine IL-33 is Inactivated After Maturation by Caspase-1. Proc Natl Acad Sci USA (2009) 106(22):9021-6. doi: 10.1073/pnas.0812690106

23. Luthi AU, Cullen SP, McNeela EA, Duriez PJ, Afonina IS, Sheridan C, et al. Suppression of Interleukin-33 Bioactivity Through Proteolysis by Apoptotic Caspases. Immunity (2009) 31(1):84-98. doi: 10.1016/j.immuni.2009.05.007

24. Lefrancais E, Roga S, Gautier V, Gonzalez-de-Peredo A, Monsarrat B, Girard JP, et al. IL-33 Is Processed Into Mature Bioactive Forms by Neutrophil Elastase and Cathepsin G. Proc Natl Acad Sci USA (2012) 109(5):1673-8. doi: 10.1073/pnas.1115884109

25. Lefrancais E, Duval A, Mirey E, Roga S, Espinosa E, Cayrol C, et al. Central Domain of IL-33 Is Cleaved by Mast Cell Proteases for Potent Activation of Group-2 Innate Lymphoid Cells. Proc Natl Acad Sci USA (2014) 111 (43):15502-7. doi: 10.1073/pnas.1410700111

26. Waern I, Lundequist A, Pejler G, Wernersson S. Mast Cell Chymase Modulates IL-33 Levels and Controls Allergic Sensitization in Dust-Mite Induced Airway Inflammation. Mucosal Immunol (2013) 6(5):911-20. doi: 10.1038/mi.2012.129

27. Chackerian AA, Oldham ER, Murphy EE, Schmitz J, Pflanz S, Kastelein RA. IL-1 Receptor Accessory Protein and ST2 Comprise the IL-33 Receptor Complex. J Immunol (2007) 179(4):2551-5. doi: 10.4049/jimmunol. 179.4.2551

28. Ali S, Huber M, Kollewe C, Bischoff SC, Falk W, Martin MU. IL-1 Receptor Accessory Protein is Essential for IL-33-induced Activation of T Lymphocytes and Mast Cells. Proc Natl Acad Sci USA (2007) 104 (47):18660-5. doi: 10.1073/pnas.0705939104

29. Liew FY, Girard JP, Turnquist HR. Interleukin-33 in Health and Disease. Nat Rev Immunol (2016) 16(11):676-89. doi: 10.1038/nri.2016.95

30. Bergers G, Reikerstorfer A, Braselmann S, Graninger P, Busslinger M. Alternative Promoter Usage of the Fos-responsive Gene Fit-1 Generates mRNA Isoforms Coding for Either Secreted or Membrane-Bound Proteins Related to the IL-1 Receptor. EMBO J (1994) 13(5):1176-88. doi: 10.1002/ j.1460-2075.1994.tb06367.x

31. Gachter T, Werenskiold AK, Klemenz R. Transcription of the Interleukin-1 Receptor-Related T1 Gene Is Initiated at Different Promoters in Mast Cells and Fibroblasts. J Biol Chem (1996) 271(1):124-9. doi: 10.1074/ jbc.271.1.124

32. Bandara G, Beaven MA, Olivera A, Gilfillan AM, Metcalfe DD. Activated Mast Cells Synthesize and Release Soluble ST2-a Decoy Receptor for IL-33. Eur J Immunol (2015) 45(11):3034-44. doi: 10.1002/eji.201545501

33. Hayakawa H, Hayakawa M, Kume A, Tominaga S. Soluble ST2 Blocks Interleukin-33 Signaling in Allergic Airway Inflammation. J Biol Chem (2007) 282(36):26369-80. doi: 10.1074/jbc.M704916200

34. Tominaga S, Kuroiwa K, Tago K, Iwahana H, Yanagisawa K, Komatsu N. Presence and Expression of a Novel Variant Form of ST2 Gene Product in Human Leukemic Cell Line UT-7/GM. Biochem Biophys Res Commun (1999) 264(1):14-8. doi: 10.1006/bbrc.1999.1469

35. Iwahana H, Hayakawa M, Kuroiwa K, Tago K, Yanagisawa K, Noji S, et al. Molecular Cloning of the Chicken ST2 Gene and a Novel Variant Form of the ST2 Gene Product, ST2LV. Biochim Biophys Acta (2004) 1681(1):1-14. doi: 10.1016/j.bbaexp.2004.08.013

36. Bulek K, Swaidani S, Qin J, Lu Y, Gulen MF, Herjan T, et al. The Essential Role of Single Ig IL-1 Receptor-Related Molecule/Toll IL-1R8 in Regulation of Th2 Immune Response. J Immunol (2009) 182(5):2601-9. doi: 10.4049/ jimmunol.0802729

37. Garlanda C, Anders HJ, Mantovani A. TIR8/SIGIRR: An IL-1R/TLR Family Member With Regulatory Functions in Inflammation and $\mathrm{T}$ Cell Polarization. Trends Immunol (2009) 30(9):439-46. doi: 10.1016/ j.it.2009.06.001

38. Zhao J, Wei J, Mialki RK, Mallampalli DF, Chen BB, Coon T, et al. F-Box Protein FBXL19-mediated Ubiquitination and Degradation of the Receptor for IL-33 Limits Pulmonary Inflammation. Nat Immunol (2012) 13(7):6518. doi: $10.1038 /$ ni.2341

39. Wicher G, Husic E, Nilsson G, Forsberg-Nilsson K. Developmental Expression of IL-33 in the Mouse Brain. Neurosci Lett (2013) 555:171-6. doi: 10.1016/j.neulet.2013.09.046

40. Vainchtein ID, Chin G, Cho FS, Kelley KW, Miller JG, Chien EC, et al. Astrocyte-Derived Interleukin-33 Promotes Microglial Synapse Engulfment and Neural Circuit Development. Science (2018) 359(6381):1269-73. doi: 10.1126/science.aal3589

41. Natarajan C, Yao SY, Sriram S. TLR3 Agonist Poly-IC Induces IL-33 and Promotes Myelin Repair. PloS One (2016) 11(3):e0152163. doi: 10.1371/ journal.pone. 0152163

42. Sung HY, Chen WY, Huang HT, Wang CY, Chang SB, Tzeng SF. DownRegulation of Interleukin-33 Expression in Oligodendrocyte Precursor Cells Impairs Oligodendrocyte Lineage Progression. J Neurochem (2019) 150 (6):691-708. doi: 10.1111/jnc.14788

43. Pichery M, Mirey E, Mercier P, Lefrancais E, Dujardin A, Ortega N, et al Endogenous IL-33 Is Highly Expressed in Mouse Epithelial Barrier Tissues, Lymphoid Organs, Brain, Embryos, and Inflamed Tissues: in Situ Analysis Using a Novel Il-33-LacZ Gene Trap Reporter Strain. J Immunol (2012) 188 (7):3488-95. doi: 10.4049/jimmunol.1101977

44. Cao K, Liao X, Lu J, Yao S, Wu F, Zhu X, et al. IL-33/ST2 Plays a Critical Role in Endothelial Cell Activation and Microglia-Mediated Neuroinflammation Modulation. J Neuroinflammation (2018) 15(1):136. doi: 10.1186/s12974018-1169-6

45. Allan D, Fairlie-Clarke KJ, Elliott C, Schuh C, Barnett SC, Lassmann H, et al. Role of IL-33 and ST2 Signalling Pathway in Multiple Sclerosis: Expression by Oligodendrocytes and Inhibition of Myelination in Central Nervous System. Acta Neuropathol Commun (2016) 4(1):75. doi: 10.1186/s40478-016-0344-1

46. Li M, Li Y, Liu X, Gao X, Wang Y. IL-33 Blockade Suppresses the Development of Experimental Autoimmune Encephalomyelitis in C57BL/ 6 Mice. J Neuroimmunol (2012) 247(1-2):25-31. doi: 10.1016/j.jneuroim. 2012.03.016

47. Chen H, Sun Y, Lai L, Wu H, Xiao Y, Ming B, et al. Interleukin-33 is Released in Spinal Cord and Suppresses Experimental Autoimmune Encephalomyelitis in Mice. Neuroscience (2015) 308:157-68. doi: 10.1016/ j.neuroscience.2015.09.019

48. Jiang HR, Milovanovic M, Allan D, Niedbala W, Besnard AG, Fukada SY, et al. IL-33 Attenuates EAE by Suppressing IL-17 and IFN-gamma Production and Inducing Alternatively Activated Macrophages. Eur J Immunol (2012) 42(7):1804-14. doi: 10.1002/eji.201141947

49. Russi AE, Ebel ME, Yang Y, Brown MA. Male-Specific IL-33 Expression Regulates Sex-Dimorphic EAE Susceptibility. Proc Natl Acad Sci USA (2018) 115(7):E1520-E9. doi: 10.1073/pnas.1710401115

50. Finlay CM, Stefanska AM, Walsh KP, Kelly PJ, Boon L, Lavelle EC, et al. Helminth Products Protect Against Autoimmunity Via Innate Type 2 Cytokines IL-5 and IL-33, Which Promote Eosinophilia. I Immunol (2016) 196(2):703-14. doi: 10.4049/jimmunol.1501820

51. Xiao Y, Lai L, Chen H, Shi J, Zeng F, Li J, et al. Interleukin-33 Deficiency Exacerbated Experimental Autoimmune Encephalomyelitis With an Influence on Immune Cells and Glia Cells. Mol Immunol (2018) 101:55063. doi: 10.1016/j.molimm.2018.08.026

52. Milovanovic M, Volarevic V, Ljujic B, Radosavljevic G, Jovanovic I Arsenijevic N, et al. Deletion of IL-33R (ST2) Abrogates Resistance to EAE in BALB/C Mice by Enhancing Polarization of APC to Inflammatory Phenotype. PloS One (2012) 7(9):e45225. doi: 10.1371/journal.pone.0045225 
53. Griesenauer B, Paczesny S. The ST2/IL-33 Axis in Immune Cells During Inflammatory Diseases. Front Immunol (2017) 8:475. doi: 10.3389/ fimmu.2017.00475

54. Zandee SEJ, O'Connor RA, Mair I, Leech MD, Williams A, Anderton SM. IL-10-Producing, ST2-Expressing Foxp3(+) T Cells in Multiple Sclerosis Brain Lesions. Immunol Cell Biol (2017) 95(5):484-90. doi: 10.1038/ icb. 2017.3

55. Du Q, Weng JF, Luo LF, Cen M, Yu WH, Zheng YK, et al. Serum ST2 as a Potential Prognostic Biomarker for Traumatic Brain Injury. Clin Chim Acta (2018) 487:145-52. doi: 10.1016/j.cca.2018.09.035

56. Gao Y, Zhang MY, Wang T, Fan YY, Yu LS, Ye GH, et al. IL-33/ST2L Signaling Provides Neuroprotection Through Inhibiting Autophagy, Endoplasmic Reticulum Stress, and Apoptosis in a Mouse Model of Traumatic Brain Injury. Front Cell Neurosci (2018) 12:95. doi: 10.3389/ fncel.2018.00095

57. Jiang M, Liu X, Zhang D, Wang Y, Hu X, Xu F, et al. Celastrol Treatment Protects Against Acute Ischemic Stroke-Induced Brain Injury by Promoting an IL-33/ST2 Axis-Mediated Microglia/Macrophage M2 Polarization. J Neuroinflammation (2018) 15(1):78. doi: 10.1186/s12974-018-1124-6

58. Chen W, Lin A, Yu Y, Zhang L, Yang G, Hu H, et al. Serum Soluble ST2 as a Novel Inflammatory Marker in Acute Ischemic Stroke. Clin Lab (2018) 64 (9):1349-56. doi: 10.7754/Clin.Lab.2018.180105

59. Andersson C, Preis SR, Beiser A, DeCarli C, Wollert KC, Wang TJ, et al. Associations of Circulating Growth Differentiation Factor-15 and ST2 Concentrations With Subclinical Vascular Brain Injury and Incident Stroke. Stroke (2015) 46(9):2568-75. doi: 10.1161/STROKEAHA. 115.009026

60. Yang Y, Liu H, Zhang H, Ye Q, Wang J, Yang B, et al. ST2/IL-33-Dependent Microglial Response Limits Acute Ischemic Brain Injury. J Neurosci (2017) 37(18):4692-704. doi: 10.1523/JNEUROSCI.3233-16.2017

61. Luo Q, Fan Y, Lin L, Wei J, Li Z, Li Y, et al. Interleukin-33 Protects Ischemic Brain Injury by Regulating Specific Microglial Activities. Neuroscience (2018) 385:75-89. doi: 10.1016/j.neuroscience.2018.05.047

62. Jiao M, Li X, Chen L, Wang X, Yuan B, Liu T, et al. Neuroprotective Effect of Astrocyte-Derived IL-33 in Neonatal Hypoxic-Ischemic Brain Injury. J Neuroinflammation (2020) 17(1):251. doi: 10.1186/s12974-020-01932-Z

63. Luo Y, Zhou Y, Xiao W, Liang Z, Dai J, Weng X, et al. Interleukin-33 Ameliorates Ischemic Brain Injury in Experimental Stroke Through Promoting Th2 Response and Suppressing Th17 Response. Brain Res (2015) 1597:86-94. doi: 10.1016/j.brainres.2014.12.005

64. Zhang SR, Piepke M, Chu HX, Broughton BR, Shim R, Wong CH, et al. IL33 Modulates Inflammatory Brain Injury But Exacerbates Systemic Immunosuppression Following Ischemic Stroke. JCI Insight (2018) 3(18): e121560. doi: 10.1172/jci.insight.121560

65. Xiao W, Guo S, Chen L, Luo Y. The Role of Interleukin-33 in the Modulation of Splenic T-cell Immune Responses After Experimental Ischemic Stroke. J Neuroimmunol (2019) 333:576970. doi: 10.1016/j.jneuroim.2019.576970

66. Liu X, Hu R, Pei L, Si P, Wang C, Tian X, et al. Regulatory T Cell is Critical for Interleukin-33-Mediated Neuroprotection Against Stroke. Exp Neurol (2020) 328:113233. doi: 10.1016/j.expneurol.2020.113233

67. Guo S, Luo Y. Brain Foxp3(+) Regulatory T Cells can be Expanded by Interleukin-33 in Mouse Ischemic Stroke. Int Immunopharmacol (2020) 81:106027. doi: 10.1016/j.intimp.2019.106027

68. Ito M, Komai K, Mise-Omata S, Iizuka-Koga M, Noguchi Y, Kondo T, et al. Brain Regulatory $\mathrm{T}$ Cells Suppress Astrogliosis and Potentiate Neurological Recovery. Nature (2019) 565(7738):246-50. doi: 10.1038/ s41586-018-0824-5

69. Huang LT, Li H, Sun Q, Liu M, Li WD, Li S, et al. IL-33 Expression in the Cerebral Cortex Following Experimental Subarachnoid Hemorrhage in Rats. Cell Mol Neurobiol (2015) 35(4):493-501. doi: 10.1007/s10571-014-0143-9

70. Gao Y, Ma L, Luo CL, Wang T, Zhang MY, Shen X, et al. IL-33 Exerts Neuroprotective Effect in Mice Intracerebral Hemorrhage Model Through Suppressing Inflammation/Apoptotic/Autophagic Pathway. Mol Neurobiol (2017) 54(5):3879-92. doi: 10.1007/s12035-016-9947-6

71. Chen Z, Xu N, Dai X, Zhao C, Wu X, Shankar S, et al. Interleukin-33 Reduces Neuronal Damage and White Matter Injury Via Selective Microglia M2 Polarization After Intracerebral Hemorrhage in Rats. Brain Res Bull (2019) 150:127-35. doi: 10.1016/j.brainresbull.2019.05.016
72. Palomo J, Reverchon F, Piotet J, Besnard AG, Couturier-Maillard A, Maillet I, et al. Critical Role of IL-33 Receptor ST2 in Experimental Cerebral Malaria Development. Eur J Immunol (2015) 45(5):1354-65. doi: 10.1002/ eji.201445206

73. Peng H, Sun R, Zhang Q, Zhao J, Wei J, Zeng X, et al. Interleukin 33 Mediates Type 2 Immunity and Inflammation in the Central Nervous System of Mice Infected With Angiostrongylus Cantonensis. J Infect Dis (2013) 207(5):860-9. doi: 10.1093/infdis/jis682

74. Jones LA, Roberts F, Nickdel MB, Brombacher F, McKenzie AN, Henriquez FL, et al. IL-33 Receptor (T1/ST2) Signalling Is Necessary to Prevent the Development of Encephalitis in Mice Infected With Toxoplasma Gondii. Eur J Immunol (2010) 40(2):426-36. doi: 10.1002/eji.200939705

75. Still KM, Batista SJ, O’Brien CA, Oyesola OO, Fruh SP, Webb LM, et al. Astrocytes Promote a Protective Immune Response to Brain Toxoplasma Gondii Infection Via IL-33-ST2 Signaling. PloS Pathog (2020) 16(10): e1009027. doi: 10.1371/journal.ppat.1009027

76. Shibui A, Takamori A, Tolba MEM, Nambu A, Shimura E, Yamaguchi S, et al. IL-25, IL-33 and TSLP Receptor Are Not Critical for Development of Experimental Murine Malaria. Biochem Biophys Rep (2016) 5:191-5. doi: 10.1016/j.bbrep.2015.12.007

77. Besnard AG, Guabiraba R, Niedbala W, Palomo J, Reverchon F, Shaw TN, et al. IL-33-mediated Protection Against Experimental Cerebral Malaria is Linked to Induction of Type 2 Innate Lymphoid Cells, M2 Macrophages and Regulatory T Cells. PloS Pathog (2015) 11(2):e1004607. doi: 10.1371/ journal.ppat.1004607

78. de Sousa JR, Azevedo RSS, Martins Filho AJ, Araujo MTF, Moutinho ERC, Baldez Vasconcelos BC, et al. Correlation Between Apoptosis and in Situ Immune Response in Fatal Cases of Microcephaly Caused by Zika Virus. Am J Pathol (2018) 188(11):2644-52. doi: 10.1016/j.ajpath.2018.07.009

79. de Sousa JR, Azevedo R, Martins Filho AJ, de Araujo MTF, Cruz E, Vasconcelos BCB, et al. In Situ Inflammasome Activation Results in Severe Damage to the Central Nervous System in Fatal Zika Virus Microcephaly Cases. Cytokine (2018) 111:255-64. doi: 10.1016/j.cyto.2018.08.008

80. Reverchon F, de Concini V, Larrigaldie V, Benmerzoug S, Briault S, Togbe D, et al. Hippocampal Interleukin-33 Mediates Neuroinflammation-Induced Cognitive Impairments. J Neuroinflammation (2020) 17(1):268. doi: 10.1186/s12974-020-01939-6

81. Yndart A, Kaushik A, Agudelo M, Raymond A, Atluri VS, Saxena SK, et al. Investigation of Neuropathogenesis in HIV-1 Clade B and C Infection Associated With IL-33 and ST2 Regulation. ACS Chem Neurosci (2015) 6 (9):1600-12. doi: 10.1021/acschemneuro.5b00156

82. Zhang JF, Wang P, Yan YJ, Li Y, Guan MW, Yu JJ, et al. IL33 Enhances Glioma Cell Migration and Invasion by Upregulation of MMP2 and MMP9 Via the ST2-NF-kappaB Pathway. Oncol Rep (2017) 38(4):2033-42. doi: 10.3892/or.2017.5926

83. Lin L, Li Y, Liu M, Li Q, Liu Q, Li R. The Interleukin-33/ST2 Axis Promotes Glioma Mesenchymal Transition, Stemness and TMZ Resistance Via JNK Activation. Aging (2020) 12(2):1685-703. doi: 10.18632/aging.102707

84. Fang KM, Yang CS, Lin TC, Chan TC, Tzeng SF. Induced Interleukin-33 Expression Enhances the Tumorigenic Activity of Rat Glioma Cells. Neuro Oncol (2014) 16(4):552-66. doi: 10.1093/neuonc/not234

85. De Boeck A, Ahn BY, D’Mello C, Lun X, Menon SV, Alshehri MM, et al Glioma-Derived IL-33 Orchestrates an Inflammatory Brain Tumor Microenvironment That Accelerates Glioma Progression. Nat Commun (2020) 11(1):4997. doi: 10.1038/s41467-020-18569-4

86. Sandler U, Devary O, Braitbard O, Ohana J, Kass G, Rubinstein AM, et al. NEROFE-a Novel Human Hormone-Peptide With Anti-Cancer Activity. J Exp Ther Oncol (2010) 8(4):327-39.

87. Xiong Z, Thangavel R, Kempuraj D, Yang E, Zaheer S, Zaheer A. Alzheimer's Disease: Evidence for the Expression of Interleukin-33 and its Receptor ST2 in the Brain. J Alzheimers Dis (2014) 40(2):297-308. doi: 10.3233/JAD-132081

88. Chapuis J, Hot D, Hansmannel F, Kerdraon O, Ferreira S, Hubans C, et al. Transcriptomic and Genetic Studies Identify IL-33 as a Candidate Gene for Alzheimer's Disease. Mol Psychiatry (2009) 14(11):1004-16. doi: 10.1038/ mp. 2009.10

89. Saresella M, Marventano I, Piancone F, La Rosa F, Galimberti D, Fenoglio C, et al. IL-33 and its Decoy sST2 in Patients With Alzheimer's Disease and 
Mild Cognitive Impairment. J Neuroinflammation (2020) 17(1):174. doi: 10.1186/s12974-020-01806-4

90. Tian M, Deng YY, Hou DR, Li W, Feng XL, Yu ZL. Association of IL-1, IL18, and IL-33 Gene Polymorphisms With Late-Onset Alzheimers Disease in a Hunan Han Chinese Population. Brain Res (2015) 1596:136-45. doi: 10.1016/j.brainres.2014.11.019

91. Yu JT, Song JH, Wang ND, Wu ZC, Zhang Q, Zhang N, et al. Implication of IL-33 Gene Polymorphism in Chinese Patients With Alzheimer's Disease. Neurobiol Aging (2012) 33(5):1014.e11-4. doi: 10.1016/j.neurobiolaging. 2010.07.003

92. Fu AK, Hung KW, Yuen MY, Zhou X, Mak DS, Chan IC, et al. IL-33 Ameliorates Alzheimer's Disease-Like Pathology and Cognitive Decline. Proc Natl Acad Sci USA (2016) 113(19):E2705-13. doi: 10.1073/ pnas. 1604032113

93. Gao Y, Tan L, Yu JT, Tan L. Tau in Alzheimer's Disease: Mechanisms and Therapeutic Strategies. Curr Alzheimer Res (2018) 15(3):283-300. doi: $10.2174 / 1567205014666170417111859$

94. Carlock C, Wu J, Shim J, Moreno-Gonzalez I, Pitcher MR, Hicks J, et al. Interleukin33 Deficiency Causes Tau Abnormality and Neurodegeneration With Alzheimer-like Symptoms in Aged Mice. Trans Psychiatry (2017) 7(7): e1164. doi: 10.1038/tp.2017.142

95. Fung ITH, Sankar P, Zhang Y, Robison LS, Zhao X, D'Souza SS, et al. Activation of Group 2 Innate Lymphoid Cells Alleviates Aging-Associated Cognitive Decline. J Exp Med (2020) 217(4):e20190915. doi: 10.1084/ jem.20190915

96. Kempuraj D, Thangavel R, Selvakumar GP, Ahmed ME, Zaheer S, Raikwar SP, et al. Mast Cell Proteases Activate Astrocytes and Glia-Neurons and Release Interleukin- 33 by Activating $\mathrm{p} 38$ and ERK1/2 MAPKs and NF-kappaB. Mol Neurobiol (2019) 56(3):1681-93. doi: 10.1007/s12035-018-1177-7

97. Kempuraj D, Thangavel R, Yang E, Pattani S, Zaheer S, Santillan DA, et al. Dopaminergic Toxin 1-Methyl-4-Phenylpyridinium, Proteins alphaSynuclein and Glia Maturation Factor Activate Mast Cells and Release Inflammatory Mediators. PloS One (2015) 10(8):e0135776. doi: 10.1371/ journal.pone.0135776

98. Liu S, Mi WL, Li Q, Zhang MT, Han P, Hu S, et al. Spinal IL-33/ST2 Signaling Contributes to Neuropathic Pain Via Neuronal CaMKII-CREB and Astroglial JAK2-STAT3 Cascades in Mice. Anesthesiology (2015) 123 (5):1154-69. doi: 10.1097/ALN.0000000000000850

99. Zarpelon AC, Rodrigues FC, Lopes AH, Souza GR, Carvalho TT, Pinto LG, et al. Spinal Cord Oligodendrocyte-Derived Alarmin IL-33 Mediates Neuropathic Pain. FASEB J (2016) 30(1):54-65. doi: 10.1096/fj.14-267146

100. Zhao J, Zhang H, Liu SB, Han P, Hu S, Li Q, et al. Spinal Interleukin-33 and its Receptor ST2 Contribute to Bone Cancer-Induced Pain in Mice. Neuroscience (2013) 253:172-82. doi: 10.1016/j.neuroscience.2013.08.026

101. Huang SJ, Yan JQ, Luo H, Zhou LY, Luo JG. IL-33/ST2 Signaling Contributes to Radicular Pain by Modulating MAPK and NF-kappaB Activation and Inflammatory Mediator Expression in the Spinal Cord in Rat Models of Noncompressive Lumber Disk Herniation. J Neuroinflammation (2018) 15 (1):12. doi: 10.1186/s12974-017-1021-4

102. Huang J, Gandini MA, Chen L, M'Dahoma S, Stemkowski PL, Chung H, et al. Hyperactivity of Innate Immunity Triggers Pain Via TLR2-IL-33Mediated Neuroimmune Crosstalk. Cell Rep (2020) 33(1):108233. doi: 10.1016/j.celrep.2020.108233

103. Lissak IA, Zafar SF, Westover MB, Schleicher RL, Kim JA, Leslie-Mazwi T, et al. Soluble ST2 Is Associated With New Epileptiform Abnormalities Following Nontraumatic Subarachnoid Hemorrhage. Stroke (2020) 51 (4):1128-34. doi: 10.1161/STROKEAHA.119.028515

104. Gao Y, Luo CL, Li LL, Ye GH, Gao C, Wang HC, et al. IL-33 Provides Neuroprotection Through Suppressing Apoptotic, Autophagic and NFkappaB-Mediated Inflammatory Pathways in a Rat Model of Recurrent Neonatal Seizure. Front Mol Neurosci (2017) 10:423. doi: 10.3389/ fnmol.2017.00423

105. Gao Y, Luo C, Yao Y, Huang J, Fu H, Xia C, et al. IL-33 Alleviated Brain Damage Via Anti-Apoptosis, Endoplasmic Reticulum Stress, and Inflammation After Epilepsy. Front Neurosci (2020) 14:898. doi: 10.3389/fnins.2020.00898

106. de Campos-Carli SM, Miranda AS, Dias IC, de Oliveira A, Cruz BF, Vieira EL, et al. Serum Levels of Interleukin-33 and its Soluble Form Receptor (sST2) Are
Associated With Cognitive Performance in Patients With Schizophrenia. Compr Psychiatry (2017) 74:96-101. doi: 10.1016/j.comppsych.2017.01.008

107. Kordi-Tamandani DM, Bahrami AR, Sabbaghi-Ghale-No R, Soleimani H, Baranzehi T. Analysis of IL-33 Gene Polymorphism (Rs11792633 C/T) and Risk of Schizophrenia. Mol Biol Res Commun (2016) 5(1):45-8. doi: 10.22099/MBRC.2016.3485

108. Kudinova AY, Deak T, Hueston CM, McGeary JE, Knopik VS, Palmer RH, et al. Cross-Species Evidence for the Role of Interleukin-33 in Depression Risk. J Abnormal Psychol (2016) 125(4):482-94. doi: 10.1037/abn0000158

109. Miller ES, Sakowicz A, Roy A, Yang A, Sullivan JT, Grobman WA, et al. Plasma and Cerebrospinal Fluid Inflammatory Cytokines in Perinatal Depression. Am J Obstet Gynecol (2019) 220(3):271.e1-e10. doi: 10.1016/j.jog.2018.12.015

110. Barbosa IG, Rodrigues DH, Rocha NP, Sousa LF, Vieira EL, Simoes ESAC, et al. Plasma Levels of Alarmin IL-33 are Unchanged in Autism Spectrum Disorder: A Preliminary Study. J Neuroimmunol (2015) 278:69-72. doi: 10.1016/j.jneuroim.2014.11.021

111. Tsilioni I, Taliou A, Francis K, Theoharides TC. Children With Autism Spectrum Disorders, Who Improved With a Luteolin-Containing Dietary Formulation, Show Reduced Serum Levels of TNF and IL-6. Trans Psychiatry (2015) 5:e647. doi: 10.1038/tp.2015.142

112. Heo Y, Zhang Y, Gao D, Miller VM, Lawrence DA. Aberrant Immune Responses in a Mouse With Behavioral Disorders. PloS One (2011) 6(7): e20912. doi: 10.1371/journal.pone.0020912

113. Dohi E, Choi EY, Rose IVL, Murata AS, Chow S, Niwa M, et al. Behavioral Changes in Mice Lacking Interleukin-33. eNeuro (2017) 4(6): ENEURO.0147-17.2017. doi: 10.1523/ENEURO.0147-17.2017

114. Lin CY, Pfluger CM, Henderson RD, McCombe PA. Reduced Levels of Interleukin 33 and Increased Levels of Soluble ST2 in Subjects With Amyotrophic Lateral Sclerosis. J Neuroimmunol (2012) 249(1-2):93-5. doi: 10.1016/j.jneuroim.2012.05.001

115. Korhonen P, Pollari E, Kanninen KM, Savchenko E, Lehtonen S, Wojciechowski S, et al. Long-Term interleukin-33 Treatment Delays Disease Onset and Alleviates Astrocytic Activation in a Transgenic Mouse Model of Amyotrophic Lateral Sclerosis. IBRO Rep (2019) 6:74-86. doi: 10.1016/j.ibror.2019.01.005

116. Farahangiz S, Sarhadi S, Safari A, Borhani-Haghighi A. Magnetic Resonance Imaging Findings and Outcome of Neuro-Behcet's Disease: The Predictive Factors. Int J Rheum Dis (2012) 15(6):e142-9. doi: 10.1111/1756-185X.12013

117. Hamzaoui K, Borhani-Haghighi A, Kaabachi W, Hamzaoui A. Increased Interleukin 33 in Patients With Neuro-Behcet's Disease: Correlation With MCP-1 and IP-10 Chemokines. Cell Mol Immunol (2014) 11(6):613-6. doi: $10.1038 / \mathrm{cmi} .2014 .31$

118. Molofsky AB, Savage AK, Locksley RM. Interleukin-33 in Tissue Homeostasis, Injury, and Inflammation. Immunity (2015) 42(6):1005-19. doi: 10.1016/j.immuni.2015.06.006

119. Malik A, Sharma D, Zhu Q, Karki R, Guy CS, Vogel P, et al. Il-33 Regulates the IgA-microbiota Axis to Restrain IL-1Alpha-Dependent Colitis and Tumorigenesis. J Clin Invest (2016) 126(12):4469-81. doi: 10.1172/JCI88625

120. Xiao Y, Huang X, Zhao Y, Chen F, Sun M, Yang W, et al. Interleukin-33 Promotes REG3gamma Expression in Intestinal Epithelial Cells and Regulates Gut Microbiota. Cell Mol Gastroenterol Hepatol (2019) 8(1):2136. doi: 10.1016/j.jcmgh.2019.02.006

121. Cryan JF, O'Riordan KJ, Cowan CSM, Sandhu KV, Bastiaanssen TFS, Boehme M, et al. The Microbiota-Gut-Brain Axis. Physiol Rev (2019) 99 (4):1877-2013. doi: 10.1152/physrev.00018.2018

Conflict of Interest: The authors declare that the research was conducted in the absence of any commercial or financial relationships that could be construed as a potential conflict of interest.

Copyright (๑) 2021 Sun, Wen, Wang, Wen, You, Wei, Mao, Wang, Chen and Yang. This is an open-access article distributed under the terms of the Creative Commons Attribution License (CC BY). The use, distribution or reproduction in other forums is permitted, provided the original author(s) and the copyright owner(s) are credited and that the original publication in this journal is cited, in accordance with accepted academic practice. No use, distribution or reproduction is permitted which does not comply with these terms. 